10. Cousin, M.A. et al. PLOS ONE 9, e90467 (2014).

11. Anonymous. Zebrafish make a splash in FDA research. http://www.fda. gov/ForConsumers/ConsumerUpdates/ucm343940.htm (U.S. Food \& Drug Administration, April, 2013).

Darya A Meshalkina ${ }^{1}$, Cai Song ${ }^{2}$ and Allan V Kalueff ${ }^{2-5}$
${ }^{1}$ Institute of Translational Biomedicine, St. Petersburg State University, St. Petersburg, Russia, ${ }^{2}$ Research Institute of Marine Drugs and Nutrition, Guangdong Ocean University, Zhanjiang, China, ${ }^{3}$ ZENEREI Institute and the International Zebrafish Neuroscience Research Consortium (ZNRC), Slidell, Louisiana, USA, ${ }^{4}$ Institute of Chemical Technologies, Ural Federal University, Yekaterinburg, Russia, ${ }^{5}$ Laboratory of Biological Psychiatry, St. Petersburg State University, St. Petersburg, Russia. Correspondence should be addressed to A.V.K. (avkalueff@gmail.com)

\section{USDA's removal of information from their website}

\section{To the editor:}

The recent removal of inspection reports, regulatory correspondence, research facility annual reports, and enforcement records that have not received final adjudication from the U.S. Department of Agriculture's Animal and Plant Health Inspection Service (APHIS) website will have an impact on registered research facilities and licensed dealers who supply animals to those facilities. The full meaning of that impact is not clear at this time. Since information that could be found on the affected website has been used by individuals and organizations opposed to the use of animals in research to target institutions through the use of misleading press releases and calls for additional inspection and enforcement actions, some might consider this a net positive impact. Since the information is still contained in the database and can still be obtained by filing a FOIA request, only time will tell what the net effect will be. Since those individuals and organizations that have been the most frequent users of information obtained from the website already seemed to have identified a number of institutions of interest, they will still be able to obtain their inspection and annual reports. The issue of access to enforcement actions should have less of an impact on the research community because research facilities make up a very small percentage of the enforcement actions that were previously posted.

However, we believe there is another potential impact on the research community because the National Association for Biomedical Research (NABR) uses the USDA database to provide accurate information to the press when issues arise concerning a member institution or the biomedical research community in general. We also use this information to monitor both the inspection and enforcement processes for consistency of application and to inform our members of the emerging trends in the process. We recently used USDA information to present a webinar on the changes that have occurred over the last decade in terms of the number of citations and level of compliance within the research community. The information paints a very positive picture of the research community's commitment, not only to the letter of law in the Animal Welfare Act, but also to the spirit of the law in terms of the welfare of the animals that must be used in research.

There are times when the transparency afforded by the availability of electronic information can be used in ways that negatively impact individual institutions and the entire biomedical research community. The ready availability of this information, when taken at face value in the larger context of the entire inspection process, depicts a community where almost $80 \%$ of the inspections result in no citations, and in 2016 only resulted in 4 citations that directly impacted animal welfare. Out of 1,100 registered research facilities, that is an impressive track record that should make the research community proud.

\section{COMPETING FINANCIAL INTERESTS}

The authors declare no competing financial interests.

\section{B Taylor Bennett \& Matthew R Bailey}

National Association for Biomedical Research, Washington, D.C. Correspondence should be addressed to B.T.B. (btbdvm@yahoo.com).

\section{Openness and transparency in animal research}

\section{To the editor:}

We do not know why the USDA took the decision to remove animal welfare information from its website. It may well be in order to protect individuals from the attentions of animal rights activists, or it may be in response to complaints that misleading or incorrect information had been published in the past. Whatever the reason, there is no doubt that the move represents a backwards step on transparency about the use of animals in research in the US, and suggests that animal research is something to be hidden behind closed doors.
In the UK, the Home Office (the Government department that regulates animal research) has, since 1876 , published detailed annual statistics on how many animals are involved, which species have been used (in the UK, all vertebrates are covered by legislation, as well as cephalopods) and which areas of research they have been used in. The number of genetically modified animals (mainly mice) that are bred but never used in research is also published.

The Home Office also produces an annual report on the work of its inspectors. This includes data on instances of non-compliance with the legislation, the majority of which are self-reported by establishments. The descriptions of what went wrong, and the resulting harm suffered by the animals involved, do not make for easy reading. But animal research should not be easy. And it should not go unscrutinized. The public should be able to find out why and 